\title{
Reply \\ Reply to Diesendorf, M. Comment on "Seibert, M.K.; Rees, W.E. Through the Eye of a Needle: An Eco-Heterodox Perspective on the Renewable Energy Transition. Energies 2021, 14, 4508"
}

\author{
Megan K. Seibert ${ }^{1, *}$ and William E. Rees ${ }^{1,2}$ \\ 1 The REAL Green New Deal Project, Albany, OR 97321, USA \\ 2 Faculty of Applied Science, School of Community and Regional Planning, University of British Columbia, \\ Vancouver, BC V6T 1Z2, Canada; wrees@mail.ubc.ca \\ * Correspondence: megan.seibert@realgnd.org
}

check for updates

Citation: Seibert, M.K.; Rees, W.E. Reply to Diesendorf, M. Comment on "Seibert, M.K.; Rees, W.E. through the Eye of a Needle: An Eco-Heterodox Perspective on the Renewable Energy Transition. Energies 2021, 14, 4508". Energies 2022, 15, 970. https:// doi.org/10.3390/en15030970

Academic Editors: Wei-Hsin Chen and Enrico Sciubba

Received: 13 October 2021 Accepted: 21 December 2021 Published: 28 January 2022

Publisher's Note: MDPI stays neutral with regard to jurisdictional claims in published maps and institutional affiliations.

Copyright: (C) 2022 by the authors. Licensee MDPI, Basel, Switzerland. This article is an open access article distributed under the terms and conditions of the Creative Commons Attribution (CC BY) license (https:// creativecommons.org/licenses/by/ $4.0 /)$.
When we published Seibert and Rees (2021) [1], we expected conflicting responses from the energy/climate/sustainability community. We were therefore somewhat surprised that most of the comments and questions that have come to us in private communications have been markedly positive, many expressing gratitude for seeing such unpopular yet evidence-based and common-sense assertions in a public forum. Some have expressed relief for no longer feeling like a lone voice or that they have privately held the same view but have been reluctant to express it for fear of backlash. Because the opposing perspective expressed in Prof. Diesendorf's critique is fairly representative of views in the modern renewables camp, we welcome the opportunity to respond to it and thank the editors of Energies for the invitation to comment.

As we show below, Diesendorf's critique in many respects typifies the strawman fallacy-he purports to address our argument but sidesteps the main issue and replaces it with one of his own. Moreover, every supposed refutation he makes concerns an issue we identified as problematic and discussed at some length. (Indeed, there are instances where it seems he hasn't actually read our paper). More positively, Diesendorf does agree with us on aspects of de-growth and potential problems surrounding mineral shortages. In the following paragraphs, we address his comments point-by-point and conclude with the fundamental question before us.

1. Diesendorf claims we asked three main questions in our paper: (1) Is it possible to build and implement the RE technology without fossil fuel (FF) inputs? (2) Is it affordable? and (3) can it be done on a climate-relevant schedule? This is not the case. While we did touch on these questions parenthetically in our assessment of so-called RE, they were hardly our main focus. As clearly indicated in the abstract and corresponding section titles, our three primary goals were to: (a) situate climate change within its broader context of ecological overshoot, (b) address myriad problems with so-called renewable energy (RE) technologies that are often overlooked, and (c) offer alternative solutions that might actually salvage civilization and the planet.

Nevertheless, let's look at Diesendorf's questions-but in the context of our primary framing, overshoot. We spent an entire page showing that climate change, along with plunging biodiversity, air/land/ocean pollution, deforestation, desertification, incipient resources scarcity, etc., "are the inevitable consequences_-indeed, parallel symptoms-of the same root phenomenon: the spectacular and continuing growth of the human enterprise on a finite planet. $H$. sapiens is in overshoot, exploiting ecosystems beyond their regenerative and assimilative capacities". This is, by definition, a fatal condition. We subsequently argued that overshoot is possible only because of the short-term availability of prodigious quantities of abundant cheap energy (fossil fuels) which have given us access to all the food and other resources needed to (over)expand the human enterprise. 
Within this framing, if the answers to the questions that Diesendorf falsely elevated were indeed positive (as many so-called RE advocates believe), it would actually be disastrous for the ecosphere and, ultimately, humanity. So-called RE would simply substitute for FF and extend overshoot, i.e., they would enable the continued degradation of the ecosphere and the destruction of essential life-support 'services.' As it turns out, however, the evidence we presented supports a negative response to his questions and hence an opportunity to advance sustainable alternatives.

2. Diesendorf states, "many detailed scenario models demonstrate the technical and economic feasibility of replacing all FF energy consumption entirely with RE and efficient energy use (EE) for the whole world, regions, countries, and states/provinces".

We acknowledged on pp 1-2 that numerous such studies exist but, as noted above, explicitly stated that one of the objectives of our analysis was to expose flaws in those studies that are often overlooked or altogether ignored. We then dedicated the next 10 pages to exposing those flaws. Diesendorf engages with none of the substance therein. Nor does he engage with our reframing of the human predicament in terms of overshoot and what this means for an entirely new narrative for a successful transition. As we explained in the introduction, the "many detailed scenario models" to which Diesendorf refers are mostly representative of the inward-looking, self-referencing attempts by the techno-industrial mainstream to maintain the status quo-what we called business-as-usual by alternative means. Such studies are relatively irrelevant in the context of overshoot.

3. Diesendorf states, "many other studies agree that the vast majority of global energy consumption (which includes transport and heat) in 100\% RE scenarios will be supplied, directly or indirectly, by renewable electricity (RElec), and that most RElec will be generated by wind and solar photovoltaics (PVs), which are already much cheaper than FF and nuclear electricity in most of the world and are still declining in costs".

Again, Diesendorf side-steps the evidence we presented refuting these claims. Moreover:

(a) There is a logical fallacy in this assertion. Simply because "many other studies agree" (i.e., assume) that certain technologies will be implemented does not necessarily mean they will-or even can-actually be implemented.

(b) The major declines in manufacturing and installation costs have already been achieved-further reductions are subject to diminishing returns. Plus, what happens in the absence of subsidies? What if the prices of metals and minerals increase with demand in the face of diminishing supplies [2]? What about the costs of replacement every couple of decades?

(c) Most importantly, we devoted little attention to the financial costs of so-called RE since our core point is that they are biophysically unsustainable to begin with. We explicitly stated that claims about cheap RE are blind to numerous 'externalized' ecological and social costs, which we outlined. Diesendorf's claim deftly but illegitimately side-steps myriad technical and economic barriers to $100 \%$ electrification.

4. "Hydroelectricity will continue to substantially contribute in some regions".

Yes, but see Section 3.1.6. Like all other so-called RE technologies, large-scale hydroelectric dams have finite life spans, are constructed with and need to be repaired using FF, and have numerous negative ecological impacts.

5. "Storage for periods of several hours will be provided by batteries; storage for periods of days to months by hydroelectricity (both once-through and pumped) and other technologies [2-5]".

See Section 3.1.4 where we note that "an entire year of production from the world's largest lithium-ion battery manufacturing facility-Tesla's \$5 billion Gigafactory in Nevada-could store only three minutes' worth of annual U.S. electricity demand". See our comment above about problems with large-scale hydroelectric storage.

6. "Scotland already obtains over $60 \%$ of its annual electricity generation and $97 \%$ of its electricity consumption from renewables, mostly wind; Denmark has $47 \%$ of its generation from wind, supplemented by 15\% from biofuels derived from agricultural residues and 3\% 
from solar PV and South Australia has 56\% of its generation from wind and solar PV. All are on track to their governments' targets of 100\% RElec generation by 2030-2035".

Data from particularly windy or sunny locations cannot logically be extrapolated to the rest of the world. For example, sunny Australia enjoys solar PV capacity factors ranging up to $25 \%$ [3] compared to $9-17 \%$ for most of Canada [4] and similar high latitudes. In any case, such data completely miss the point of our paper, which is that so-called RE buildouts involve significant, wide-ranging ecological and social degradation, are not currently viable in the absence of FF, and ignore the meta-problem of overshoot.

7. "To go from $100 \%$ RElec to $100 \%$ RE requires the electrification of transport and non-electrical heating. The technologies are commercially available for both of these energy uses".

We are unclear what Diesendorf means by going "from $100 \%$ renewable electricity to $100 \%$ renewable energy". For difficulties concerning the electrification of transportation, see Section 3.1.15; for non-electrical heating, see Section 3.1.2 (Heat for Manufacturing) and Section 3.1.10 (Hidden Fossil Fuel Subsidy). The bottom line, which we continue to drive home, is that modern techno-industrial (MTI) manufacturing, which produces all of the technologies Diesendorf refers to (without specification), will not be viable in the absence of FF.

8. "Battery prices are falling globally as the market expands".

Consider again our earlier comment about financial costs. Falling prices are irrelevant considering that batteries are toxic, ecologically destructive, reliant on a dwindling and finite supply of non-renewable resources, and producible only in the context of MTI manufacturing.

9. Long-distance air and sea transports still require research and development to reduce the cost of producing hydrogen and ammonia by electrolysis using RElec, but these together account for only about $5 \%$ of total global greenhouse gas (GHG) emissions. So far, little has been done to electrify heating by FF, but there are no major technical barriers- the main barrier is sunk costs".

Diesendorf's comment about GHG emissions ignores one of our central points that the narrow focus on climate change/carbon will lead nowhere unless we address the meta-problem of overshoot. Regarding hydrogen, we say "the single greatest problem with producing hydrogen is that, regardless of method, more energy is required to produce and compress the product than it can later generate. The only viable, large-scale feedstock for hydrogen is natural gas, and the gas reforming process requires temperatures ranging from $1300 \mathrm{~F}$ to $1830 \mathrm{~F}$ ( $700 \mathrm{C}$ to $1000 \mathrm{C}$ ). Gas reforming produces substantial greenhouse gas (GHG) emissions and presents numerous problems in the way of leakage, corrosion, and accidental combustion". Diesendorf's claim that there are no technical barriers to the electrification of (presumably?) high-temperature heat in manufacturing is astounding. As we say in Section 3.1.2, electrification of all manufacturing processes would require entire system re-designs and would be prohibitively expensive. He gives no examples of the supposedly established technologies. Even so, so-called RE technologies cannot build themselves from the ground up, making the issue of electrification a moot point.

10. Diesendorf says we "Cit[e] a rhetorical statement by Clack et al. claiming errors in Jacobson et al. [3] without citing the point-by-point refutation by Jacobson et al".

First, the original conclusion made by Clack et al. was not rhetorical, and Clack et al. subsequently rejected the Jacobson et al. rebuttal [5]. Second, it is precisely the narrow and untenable set of assumptions represented by Jacobson's body of work that we highlighted and exposed as flawed throughout the paper. He treats so-called RE as black boxes, assuming they can be manufactured (or maintained, in the case of hydropower) in perpetuity and without serious negative impacts to the ecosphere and humans. Moreover, does Diesendorf expect us to follow up every citation with their litany of countervailing viewpoints/conclusions? This would be a pointless exercise that would distract from our overshoot framing and lead to impossibly long and distracting manuscripts. 
11. Claiming that 'solar PV has a low energy return on energy invested (EROEI or EROI) - too low to power modern civilization ', without citing the studies that obtain a different result or those that find that static EROEIs of FF electricity technologies are similar to those of solar PV and much less than those of wind. Different authors obtain different results by the choice of different methods and regions with different insulations. Failing to distinguish between static EROEI, which depends on the properties of the individual energy technology, its pattern of use, and its location, and dynamic system EROEI, which also depends on the rate of implementation of a system of new technologies. A rapid implementation, in which new technologies are built before existing technologies have generated the energy needed to build themselves, will inevitably decrease system EROEI temporarily. However, because wind and solar technologies can be manufactured and installed more rapidly than any other energy supply technology, they are likely to have the smallest reduction in dynamic EROEI of any energy supply technology.

First, it is important to note that we devoted two sentences out of a 15-page manuscript to EROI, both as footnotes in their respective sections following more robust and straightforward points. Second, as Diesendorf acknowledges, EROI is a complex area of research in which a spectrum of results can be achieved depending on the authors' assumptions, boundaries, data sets, modeling techniques, etc. For this reason, we recognize that it might have been wise to omit EROI from our analysis to avoid entering into this tangled web. That said, some important factors contributing to varying results are:

- Incomplete boundaries. Some EROI studies consider only the energy involved in manufacturing and installing the equipment on-site (with variations on the theme). Those who find low EROI values have usually undertaken an extended life-cycle approach, including the energy involved in the mining, refining, and transporting of materials; roads and shipping services; manufacturing; battery and pumped storage backup; additional grid connections; maintenance; decommissioning; etc.

- Redundancy. So-called RE is available only about one-third of the time, which means that the cost of storage/redundancy should be incorporated. How much redundancy depends on penetration-higher penetration may halve the EROI, and whole-system penetration may drop EROI even further.

- Varying, or untransparent, uses of quality factor conversions. Because one unit of solar $\mathrm{PV} /$ wind electricity is the electricity equivalent of $\sim 3$ units of fossil energy, solar PV and wind are sometimes multiplied by 3 to arrive at a 'fossil electricity equivalent.' Conversely, if RE were put to use doing some of the non-electrical things FF do, $\sim 3$ units of RE for 1 unit of FF would be needed-so the solar PV/wind values would have to be divided, not multiplied, by $\sim 3$. Absent clear statements by authors of published studies-about whether quality factor conversions are used, and if so, in 'which direction' - we may not know whether numbers reflect a FF electricity equivalent or a FF thermal equivalent. Indeed, oftentimes there is not such transparency.

- Different assumptions about technology efficiency. Theoretical efficiencies, or efficiencies advertised by manufacturers, are often less (sometimes significantly less) than in-the-field performance.

12. "Making, in effect, the unreasonable demand that the whole life cycle of RE technologies be instantaneously switched from FF to RE. That transition is underway in mining, mineral processing, aluminum smelting, battery manufacture, transport, retail, computer hardware, software, and so forth, with over 300 large companies committed to transition to $100 \%$ RElect by specific dates. Because of RElec's favorable economics, there is no major barrier, apart from sunk costs, to accelerating this transition".

This is an inaccurate characterization. We made no "demands", but simply stated that, for an energy source to be renewable, it would have to be capable of generating the energy to both build itself from the ground up and provide additional surplus for society-and that currently no so-called RE technology satisfies those basic criteria, nor are any poised to any time soon. Moreover, commitments made by corporations are entirely different than what is actually being done and what is actually possible. 
13. "Claiming that $100 \%$ RElec would require a much higher construction rate for the grid in the USA. Since the current construction rate is low, this is not necessarily a problem for Questions 1 and 2, although it is relevant to Question 3. Transmission costs are generally a small fraction of the cost of the generating system".

This misses the point that the grid construction rate for so-called RE would have to be more than an order of magnitude greater than the construction rate during the last half-century when FF use was pervasive and growing. To achieve such a grid construction rate now, with a limited FF/carbon budget and in a much-condensed time frame, would be next to impossible and, again, irrelevant in the context of overshoot.

14. "Exaggerating the importance and difficulty of overcoming many other 'problems' with RE technologies, most of which are temporary and/or contingent on government policies".

It is remarkable that, after critiquing us for not including Jacobson's rebuttal to Clack et al. (in the single sentence in which it appeared) and not including EROI results that we deemed narrowly focused (in the two sentences in which we mentioned EROI), Diesendorf then brushes over 10 pages' worth of what he calls so-called problems (implied by his use of quotations) with RE by saying nothing more than that we "exaggerated".

15. "Demand for some technology-specific materials will increase many times and may exceed known reserves before 2050 unless policies are implemented to reduce demand by design for disassembly, recycling, substitution, and improved efficiency of manufacturing. Furthermore, the environmental and social impacts of supply, especially in countries with little regulation of mining, must be reduced. This is an issue for the whole global economy, not just RE. Changing to a circular economy would be a step in the right direction, but this has limitations, and a more radical change to the economy is needed, as discussed in the next section".

Diesendorf is correct in pointing out that "demand for some technology-specific materials will increase many times and may exceed known reserves before 2050", but his proposal for how to address this problem is based on the wishful thinking of the so-called circular economy. As we made clear, so-called RE technologies would require continuous replacements in perpetuity. No amount of efficiency or recycling can turn a non-renewable resource into a renewable one. Recycling still requires significant energy and material inputs, not to mention the handling and disposal of toxic substances. Some materials can be recycled only so many times before losing their integrity, still necessitating the extraction of virgin ore. Quoting Michaux (2021) in detail:

"Base metals like $\mathrm{Al}, \mathrm{Cu}$, and Fe can be recycled with mature processes to a high degree of stream recovery. Precious metals like Au, Ag and PGE can also be recycled through more complex process methods. This has been developed due to the high value of the target metals. The recycling of technology metals is either not done very well, or not done at all. Recycling also can only be done so many times before the feedstock becomes useless. Natural laws such as physics and thermodynamics determine the maximum achievable recycling rate as a function of the quality of the recycling (side stream intermediate) products (Reuter et al., 2006). It can be concluded that the recyclability of a product is not only determined by the intrinsic property of the different materials used, but by the quality of the recycling streams (Reuter et al., 2006). This material stream quality is determined by the mineral classes (combination of materials due to design, shredding, and separation), particle size distribution and degree of liberation (multi-material particles), and the efficiency of physical separation. This implies that waste streams cannot be recycled indefinitely before they need to be valorized by some other form. This is something that is not included in current thinking. Current recycling rates will resemble these extraction efficiencies. The majority of infrastructure and technology units needed to phase out fossil fuels have yet to be manufactured. Recycling cannot be done on products that have yet to be manufactured. The current focus of the Circular Economy development is recycling, with the perception that mining of mineral resources is not relevant. However, the system 
to phase out fossil fuels (whatever that is) has yet to be constructed, and this will require a historically unprecedented volume of minerals/metals/materials of all kinds".

This said, we highlight again the underlying problem that modern industrial recycling processes are not viable in the absence of FF.

16. "The earth's environment needs both a radical technological change (i.e., transition to an energy system based on RE and EE) and a reduction in consumption (i.e., degrowth to an ecologically sustainable steady-state economy with reduced use of energy, materials, and land and a population that is not growing). This has been the conclusion of researchers for several decades, but surprisingly, Seibert and Rees cite none of them, creating the incorrect impression that they are discovering degrowth for the first time. The case for degrowth is robust and does not have to depend on flawed arguments that $100 \%$ RE is technically infeasible and unaffordable".

We agree that reductions in energy/material consumption, and a halt to human population growth, are needed. However, Diesendorf conflates arguments. "De-growth" has many flavors, including the one he described-which is not our position, nor is it the position of all the authors he cites. We made no ridiculous claim to novelty in discovering degrowth. What is new is our view (certainly not widely held-can he point to anyone else delivering this message in total?) that the real issue is overshoot; that so-called renewables are not, in fact, renewable and cannot substitute quantitatively or qualitatively for FF (which is actually a good thing for the planet); that we need massive absolute reductions in both the global population and energy/material consumption (as opposed to merely population stabilization) accompanied by a radical transformation of societal infrastructure and functioning; and that truly renewable energy will include biomass, simple water, and wind-based mechanical generation, passive solar, and human and animal power.

17. "Limiting global population can contribute to the transition to a steady-state economy, but there is no way-apart from nuclear war, pandemic or climate disaster-of bringing the population down to anywhere near S\&R's target of one billion by 2050 in time to avoid devastating climate change. The global one-child policy suggested by S\&R could not be implemented rapidly, if at all, because the people of low-income countries would need a social security system before they agreed. Yet, time is of the essence. Once again, S\&R have failed to substantiate their vision by doing the basic arithmetic. Furthermore, the failure to reduce global population dramatically, combined with S\&R's proposed resettlement of dense urban populations in rural areas, would devastate biodiversity".

First, it is difficult to reconcile the contradictory statements that there is no way to substantially reduce the population by 2050 and that failing to do so, combined with resettlements, would devastate biodiversity. Diesendorf seems to say that while it is impossible, on the one hand, to sizably shrink populations, not doing so, on the other, would be disastrous. Moreover, we are left wondering whether he is arguing for merely halting population growth (per his above comment in \#16) or shrinking populations (per this comment). Regardless, the human enterprise is in overshoot whether we like it or not, and whether planned or not, the human population will fall dramatically this century. This is not our plotting but rather the inevitable outcome of population ecology.

Second, we did not advocate for a target of one billion by 2050 . We stated that (a) the global carrying capacity is roughly one billion (implying, again, that the population will come down whether through planning or disaster), (b) the global population urgently needs to be reduced as quickly as possible to minimize widespread suffering, and (c) a global one-child fertility standard "implemented within a decade or two would still leave us with about three billion souls by the end of the century". We agree, per Diesendorf's last point, that resettlements, combined with a failure to dramatically reduce the global population, would be disastrous-hence why we advocated for urgently reducing the global population as quickly as possible. Diesendorf puzzlingly invents a claim we did not make and then uses our own logic to argue against it.

18. "If we were to believe their erroneous claim that $100 \% \mathrm{RE}$ is impossible without FF inputs, then, to achieve their dystopian version of degrowth, several billion people (at least) 
would have to migrate to rural areas resulting in extensive land clearing and devastating impact on biodiversity. They would have to discard electricity and cars, and heat their new homes with firewood, thus increasing air pollution and biodiversity loss. Their scenario would be disastrous for the environment, human health and wellbeing, the economy, and social justice. Fortunately, a global energy system that is entirely renewable, with little or no use of bioenergy, is technically feasible and affordable, and is already evolving towards independence from FF".

a. Diesendorf claims it is "erroneous" to state that so-called renewable cannot be made without FF, yet he engages with none of the detailed evidence we provided explaining why this is the case. And while we did not explicitly say that there will be no electricity or cars in a non-fossil energy regime, the impossibility of maintaining MTI civilization in the absence of FF does indeed imply these two points. (Notice the deftness with which he communicates this by saying that we, personally, "would have" the future look this way, as if it is a matter of our opinion rather than biophysical reality).

b. He claims it would be "dystopian" for people living in vulnerable coastlines and unsustainable dense urban centers to migrate because of the demands they would place on new land areas. However, as readily shown by eco-footprint analysis, urban dwellers already place massive demands on rural areas [6]. Indeed, cities are almost entirely subsided by their hinterlands, both proximate and global, which provide food and other materials, not to mention the energy to transport them, and assimilate exported waste. This leads us to ask how it is not dystopian for existing coastal communities to be flooded or for cities' entropic bubbles to be cut off from life-supporting hinterlands by the steep decline in exogenous energy inputs? The reality is that we have backed ourselves into a corner; there is no simple, easy course of action. Failure to do planned resettlements is a death sentence for millions, and embarking on such an ambitious endeavor would have to simultaneously involve population reductions-as we explicitly stated and Diesendorf ignores—-so as not to overwhelm the land bases of the newly settled areas.

c. Diesendorf claims that "our scenario" would be disastrous for the environment whilst ignoring the copious evidence we provided showing that a transition to so-called renewables would be disastrous for the ecosphere and that planned population reduction is essential for minimizing negative feedbacks imposed by Nature (e.g., food shortages (agriculture is largely FF dependent), climate change, ecosystems collapse). As reiterated above, "our scenario" (i.e., our call for a one-planet living endpoint) involves one billion or so people using truly renewable sources of energy while restoring ecosystems, along with a coarse-grain path for how to get there. By definition, one-planet living is not dystopian.

In summary, the techno-optimist view held by Diesendorf overlooks the fact that MTI civilization-of which so-called RE technologies are a product-is: (1) entirely subsidized by a one-off inheritance of energy-rich $\mathrm{FF}$, for which there are no known quantitative or qualitative replacements, and (2) inherently destructive of the ecosphere. Diesendorf seems oblivious to our documented argument that the notion of a "clean and green" version of MTI society - with less consumption here and more recycling and efficiency there - is not just an impossible pipedream but, if realized, would actually exacerbate overshoot because it would simply be business-as-usual by alternative means. As the authors of Bright Green Lies piercingly compel us to ask, is our goal to sustain MTI civilization or Gaia and all her inhabitants? Our choice is the latter.

Author Contributions: Writing-original draft preparation, M.K.S.; writing-additional content, W.E.R.; review and editing-M.K.S., W.E.R. All authors have read and agreed to the published version of the manuscript.

Funding: This research received no external funding.

Institutional Review Board Statement: Not applicable.

Informed Consent Statement: Not applicable. 
Data Availability Statement: Not applicable.

Conflicts of Interest: The authors declare no conflict of interest.

\section{References}

1. Seibert, M.K.; Rees, W.E. Through the Eye of a Needle: An Eco-Heterodox Perspective on the Renewable Energy Transition. Energies 2021, 14, 4508. [CrossRef]

2. Pickerel, K. Solar Prices Are up across All Markets due to Supply Chain Constraints, Threat of New Tariffs. Solar Power World, 14 September 2021. Available online: https://www.solarpowerworldonline.com/2021/09/solar-prices-are-up-across-allmarkets-due-to-supply-chain-constraints-threat-of-new-tariffs / (accessed on 9 November 2021).

3. Parkinson, G. Australia's Best Performing Wind and Solar Farms in May. Renew Economy, 10 June 2020. Available online: https: / / reneweconomy.com.au/australias-best-performing-wind-and-solar-farms-in-may-64699/ (accessed on 11 October 2021).

4. Canada Energy Regulator. Economics of Solar Power in Canada-Results. Available online: https://www.cer-rec.gc.ca/en/dataanalysis / energy-commodities/electricity/report/solar-power-economics/economics-solar-power-in-canada-results.html (accessed on 11 October 2021).

5. Clack et al. Response to Jacobson et al. Rebuttal. Available online: https://www.vibrantcleanenergy.com/wp-content/uploads / 2017/06/ReplyResponse.pdf (accessed on 12 October 2021).

6. Rees, W.E. Cities as Dissipative Structures: Global Change and the Vulnerability of Urban Civilization. In Sustainability Science; Weinstein, M.P., Turner, R.E., Eds.; Springer: New York, NY, USA, 2012; pp. 247-273, ISBN 9781461431879. 